$$
\begin{array}{r}
\text { GEAP-12114-4 } \\
\text { BHO-68-4 } \\
\text { UC-15 }
\end{array}
$$

AEC RESEARCH AND DEVELOPMENT REPORT

JANUARY 1971

\title{
INTEGRATED SAFEGUARDS EXPERIMENT
}

\section{SECOND QUARTERLY REPORT SEPTEMBER - NOVEMBER 1970}

D.C. WADEKAMPER L.T. HAGIE

\section{U.S. ATOMIC ENERGY COMMISSION} CONTRACT AT(30-1)-68 


\section{DISCLAIMER}

This report was prepared as an account of work sponsored by an agency of the United States Government. Neither the United States Government nor any agency Thereof, nor any of their employees, makes any warranty, express or implied, or assumes any legal liability or responsibility for the accuracy, completeness, or usefulness of any information, apparatus, product, or process disclosed, or represents that its use would not infringe privately owned rights. Reference herein to any specific commercial product, process, or service by trade name, trademark, manufacturer, or otherwise does not necessarily constitute or imply its endorsement, recommendation, or favoring by the United States Government or any agency thereof. The views and opinions of authors expressed herein do not necessarily state or reflect those of the United States Government or any agency thereof. 


\section{DISCLAIMER}

Portions of this document may be illegible in electronic image products. Images are produced from the best available original document. 


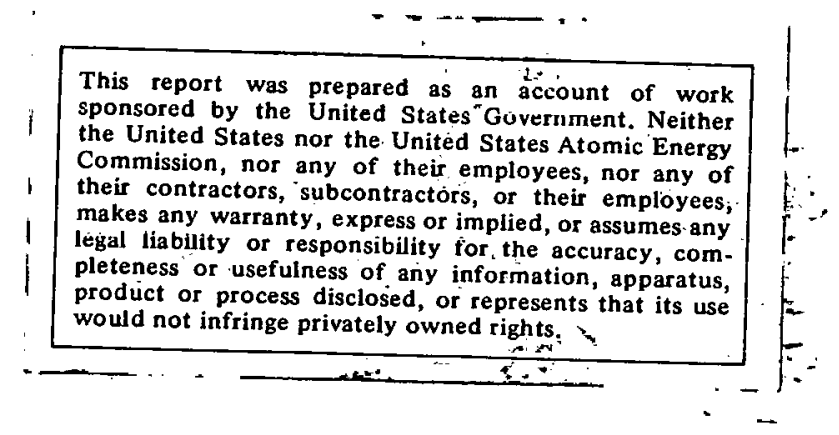

\section{INTEGRATED SAFEGUARDS EXPERIMENT \\ Second Quarterly Report \\ September - November 1970}

compiled by

D. C. Wadekamper and L. T. Hagie

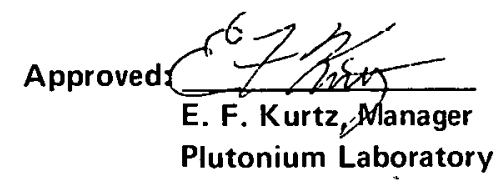

Plutonium Laboratory

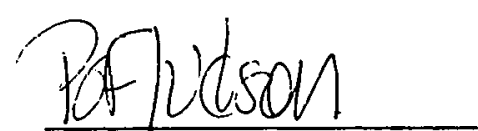

B. F. Judson, Manager

Plutonium Fuels Development

Prepared for the

United States Atomic Energy Commission

Contract No. AT(30-1)-68

Printed in U.S.A. Available from the

Clearing House for Federal Scientific and Technical Intormation

National Bureau of Standards, U.S. Department of Commerce

Springfield, Virginia 22151

Price: Printed Copy \$3.00; Microfiche $\$ 0.65$ 


\section{LEGAL NOTICE}

This report was prepared as an account of work sponsored by the United States Government. Neither the United States nor the United States Atomic Energy Commission, nor any of their employees, nor any of their contractors, subcontractors, or their employees, makes any warranty, express or implied, or assumes any legal liability or responsibility for the accuracy, completeness or usefulness of any information, apparatus, product or process disclosed, or represents that its use would not infringe privately owned rights. 


\section{CONTENTS}

\section{Page}

ABSTRACT . . . . . . . . . . . . . . . . . . . . . . . . 1

I. INTRODUCTION . . . . . . . . . . . . . . . . . . . . . . 1

II. SUMMARY . . . . . . . . . . . . . . . . . . . . . . 2

III. TASK 1. HISTORICAL DATA AND EXPERIMENTAL PLANNING . . . . . . . 2

IV. TASK 2. EXPERIMENTAL TESTING . . . . . . . . . . . . . . . . . . . . . . . . . 5

V. MiScellaneOUS . . . . . . . . . . . . . . . . . . . . . . . 22 


\title{
INTEGRATED SAFEGUARDS EXPERIMENT \\ Second Quarterly Report \\ September - November 1970 \\ compiled by
}

D. C. Wadekamper and L. T. Hagie

\begin{abstract}
The first Integrated Safeguards Experiment, ISE Campaign 1, was completed and the second experiment, ISE Campaign 2, was inititated. Material balance calculations for two historical campaigns were completed. The plutonia feed measurements for two historical campaigns as well as ISE Campaigns 1 and 2 were reviewed and analyzed. Trial material balances and total oxide balances for ISE Campaign 1 were completed. Available ISE Campaigns 1 and 2 measurement and processing data applicable to material balance accounting are summarized. A brief explanation of the present Mechanized Accountability and Criticality System is presented.
\end{abstract}

\section{INTRODUCTION}

The General Electric Company has entered into a contract with the United States Atomic Energy Commission, Contract Number AT(30-1)-68, to support technical activities associated with the Integrated Safeguards Experiment. The program is sponsored by the Office of Safeguards and Materials Management and administration is provided by the Brookhaven office. The definition of program technical objectives as well as technical direction are provided through the Brookhaven National Laboratory - Technical Support Organization.

The purpose of the Integrated Safeguard Experiment is to evaluate the usefulness to safeguards of material balance techniques that employ data based completely on measurements. Normal production and product certification data for Sperial Nuclear Material are being coupled with information obtained from nondestructive assay measurements accomplished with equipment provided on the General Electric portion of the Plant Instrumentation Program. (The purpose of the United States Atomic Energy Commission's Plant Instrumentation Program is to demonstrate the usefulness to safeguards of nondestructive assay measurements on Special Nuclear Material.) The necessary material balance information is being compiled under actual fuel fabrication conditions during three processing campaigns. Qver-all prngram objectives were formulated to demonstrate to the nuclear industry the usefulness of material balance accounting for safeguards.

During most of the contract period, Integrated Safeguards Experiment personnel have been on-site at the General Electric Company Vallecitos Nuclear Center, Pleasanton, California. These personnel, Integrated Safeguards Experiment - Technical Representatives, work jointly with General Electric personnel during planning and data evaluation of test experiments.

Pursuant to the program objectives, the initial phases of the Integrated Safeguards Experiment consisted of evaluation of historical data and planning for future testing. The following guidelines were established to provide for administratiun of the program.

Task 1 - Historical Data and Experimental Planning

Task 2 - Experimental Testing

Task 3 - Program Evaluation arid Final Report 
Technical effort was continued by the General Electric Company during the reporting period in the areas of Task 1 and 2. The existing scope of work includes: (a) evaluation of historical data applicable to material balance accounting, (b) planning and testing during production runs in which material balance accounting is accomplished with only measured quantities, (c) demonstration of a mechanized accountability system, and (d) preparation of a nonproprietary file on the accuracy and precision of all measurements.

This is the second in a series of quarterly progress reports written in partial fulfillment of Contract Number AT(30-1)-68. The reporting period is September - November 1970. The previous report in this series was GEAP-12114-2.

\section{SUMMARY}

Work efforts were continued during the reporting period under Brookhaven National Laboratory - Technical Support Organization technical direction to plan experimental test designs for future activities and to evaluate the data applicable to material balance accounting obtained from the fabrication experiments.

Evaluation of the historical data from two fabrication campaigns resulted in measurement differences of -1.44 and $+0.19 \%$ for the amount of plutonium in the feed material. Material balance calculations utilizing the historical data resulted in material unarcounted for (MUF) values of the same order of magnitude as those observed by another plutonium facility. Material balance calculations made by different analysts exhibited calculation inconsistencies which resulted in different MUF values. A method for eliminating these inconsistencies is suggested in the report.

A comparison of the amount of plutonium in the feed material for Integrated Safeguards Experiment (ISE) Campaign 1 indicated the individual measurement difference ranged from -1.54 to $+0.33 \%$. Trial material balance and limit of error calculations for ISE Campaign 1 resulted in significant plutonium MUFs of 1.40 and $1.71 \%$ for enrichments 1 and 2 . The total oxide balances prepared for each criticality limit area resulted in gains and losses of the material used. Experience has shown that these gains and losses are a part of normal processing. An evaluation of the various measurements made on ISE Campaign 2 feed indicated the plutonium measurement differences ranged from - 1.03 to $+0.31 \%$. A summary of the Mechanized Accountability and Criticality System is presented.

\section{TASK 1. HISTORICAL DATA AND EXPERIMENTAL PLANNING}

\section{A: TASK 1A. HISTORICAL DATA}

\section{General}

Historical data for two campaigns were transmitted to the Integrated Safeguards Experiment - Technical Representatives during the last reporting period. These data were used to generate material balances which result in MUF values for both campaigns.

\section{Feed Material}

Two separate plutonia feed lots were used for fuel fabrication during the historical campaigns (Table 1). General Electric Company plutonium assay measurements indicated the amount of plutonium in the feed for historical Campaign A were $1.44 \%$ lower than those made by the shipper (Atlantic Richfield Hanford Company). Since these assay measurements were some of the first made on plutonia by General Electric, the shipper's value was accepted for accountability. Additional plutonium assay measurements were made on the feed lot before its use in ISE Campaign 1. These measurements indicated the amount of plutonium in the feed was $0.75 \%$ lower than the shipper's value. It appears difficult to resolve this shipper-receiver difference because the sampling techniques did not allow for mositure absorption. Since the amount of moisture absorption during receiving inspection and storage was not determined, the uncertainty in the plutonium assay of this feed lot could not be verified.

The fabrication schedule necessitated the use of the shippers plutonium assay value for historical Campaign B. General Electric verification was based on a value calculated from plutonium isotopic and oxygen-to-plutonium ratio data. 
TABLE 1. ISE Historical Feed Measurements

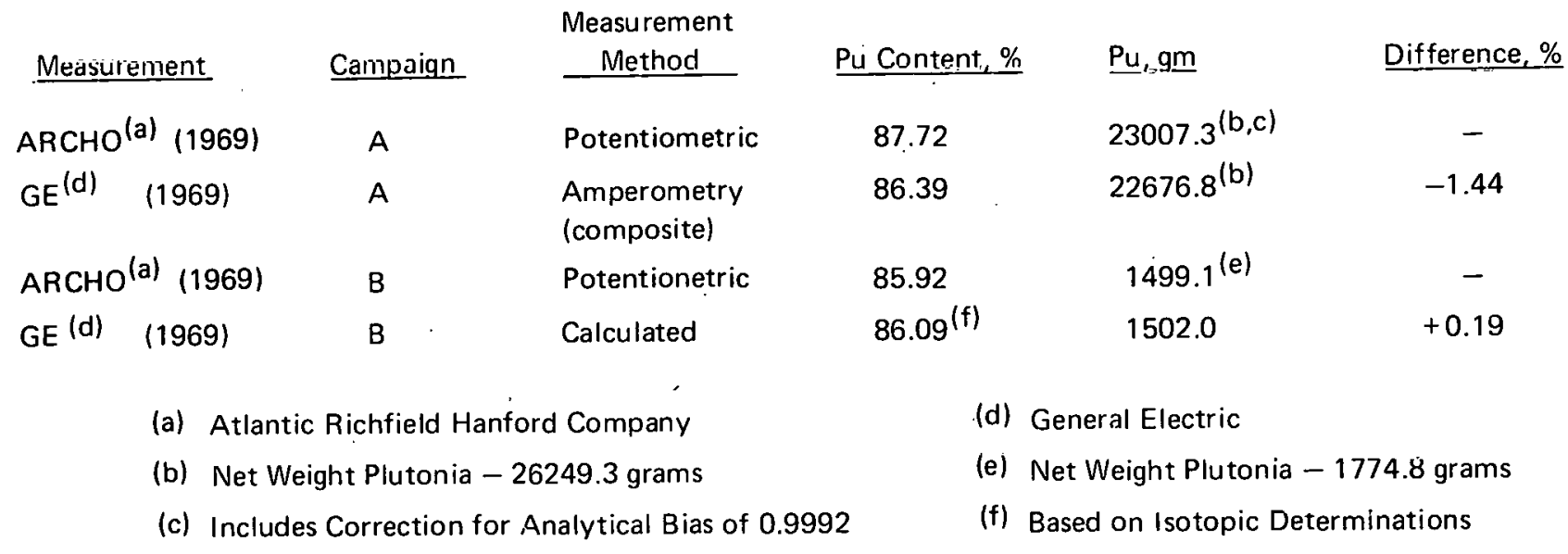

3. Material Balances

The Integrated Safeguards Experiment - Technical Representatives and General Electric personnel considered many different ways of constructing material balances for the historical campaigns. A material balance can be made in terms of total oxide (including urania, plutonia, or combinations of both), total metal, or total plutonium. There seemed to be a computational advantage in using the oxide weights, since the weights were made during normal processing. When this balance was completed, the MUF in grams of plutonium or uranium was obtained by applying the nominal percent metal and concentration factors. One major difficulty in this approach was that the nominal percent metal and concentration factors may not have been exactly attained and a bias was introduced into the total balance. A second difficulty was that some of the feed material and intermediate product remained in the ending inventory. This material has different percent metal and concentration factors than the product and again the temptation was to use the nominal values. If nominal values were used, not only would a bias be introduced, but heterogeneities in the green powder and feed material would compound the errors caused by applying nominal factors to quantities obtained by direct weighing or subtraction of two separate weights.

At least three different material balances were prepared from the available historical data. The basic type was a total oxide balance which utilized both measured and estimated oxide values obtained during routine fuel fabrication. A second balance was prepared by applying theoretical metal concentration factors as well as the nominal target value for plutonium enrichment to the total oxide balance. The third balance utilized the normal process control and product certification data to obtain actual measured values of plutonium for many of the streams in the total oxide balance. None of these balances were based completely on measurements and none were free from the use of nominal values. In this regard, none of the balances were satisfactory for the demonstration of safeguards control desired by the ISE.

The material balance presented in Table 2 was prepared by applying theoretical metal concentration. values as well as the nominal target value for plutonium enrichment to the total oxide balance (second balance type). This type of calculation was also used to maintain accountability control during actual processing. Material balance calculations, made by using the shipper's value for plutonium assay, resulted in a plutonium MUF of $1.54 \%$ for Campaign A and $0.16 \%$ for Campaign B. If the General Electric Company plutonium assay value was used for the feed material, the amount of Campaign A feed would be reduced by 331.2 grams and result in a plutonium MUF of $0.09 \%$. The MUF values reported* for Atlantic Richfield Hanford Company's Plutonium Processing Operation, 0.5 to $1.2 \%$ (throughputs of 2000 to 300 kilograms, respectively) were inversely proportional to the throughput. The MUF values obtained from the historical data were of the same magnitude as the reported values. However, the throughput was somewhat smaller (23 kilograms).

\footnotetext{
* Safeguards Capabilities of the Material Balance Accounting Systems of the Plutonium Processing and Scrap Recovery Operations at Hanford, June 1970, BNW-1399.
} 
TABLE 2. Material Balances ${ }^{(a)}$ - Historical Campaigns

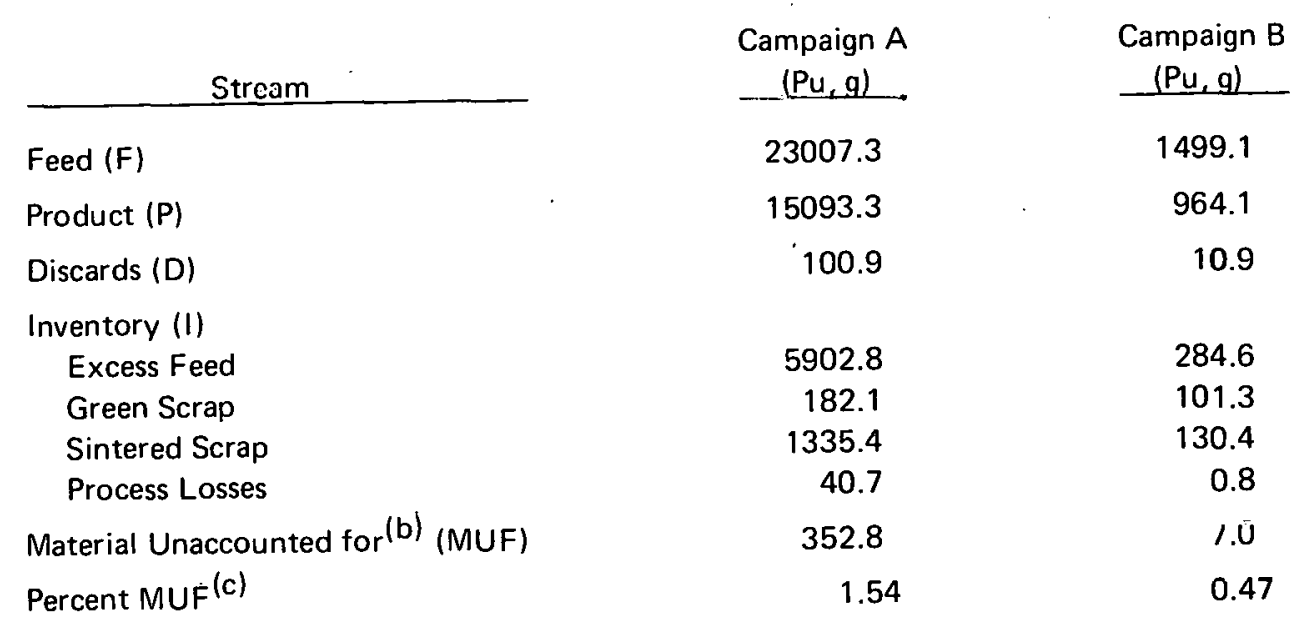
(a) Obtained by applying theoretical metal concentration factors and nominal target plutonium enrichment values used for accountability control to the total oxide balance.

(b) $\mathrm{MUF}=\mathrm{F}-(\mathrm{P}+\mathrm{D}+\mathrm{I})$

(c) Based on total input

\begin{abstract}
Although some of the measured quantities could be associated with measurement limits of error, this was not true for all the values. The quantity entered for discard was composed partly of measured samples and partly of estimated process losses. Some of the recycle and dirty scrap values were determined as by-difference weighings. As a result, even if meaningful limits of error were available for all other measured quantities, the material balance limit of error could not be calculated.
\end{abstract}

For the historical data, the calculated MUF provides a meaningful base case for the method of calculation before the ISE. The method of determining fuel product, scrap, and recycle values has been duplicated for the ISE campaigns; however, values based on estimates were not included.

The material balance prepared from historical data is of great value to safeguards because it indicates the dıtfıculty of defining the quantities to be used in a material balance calculation. Each analyst examining the data produced a slightly different balance. If MUF is to be used as a criterion of control, not only must it be composed of values that are measured and have associated limits of error, but also it must be calculated consistently from period to period. In fact this second requirement, seldom expressed in the literature, is as important as the requirement for measurement. The Mechanized Accountability and Criticality System under General Electric funded development for criticality control, safeguards, transfer and inventory accounting is being designed to generate limits of error on individual quantities and combined limits of error on programmed MUF calculations. A major advantage of such a system is that once it is programmed, MUF calculations will always be consistent or if the program is changed, the basis of the new calculation is readily comparable with that previously used.

\title{
B. TASK 1B. EXPERIMENTAL PLANNING
}

1. General

All the experimental test designs, with the exception of ISE Campaign 3, required by the contract Scope of Work were completed. Information obtained during ISE Campaign 1 led to modification of several existing test designs. 


\section{Experimental Test Designs}

Each test design was developed and evaluated jointly by Integrated Safeguards Experiment - Technical Representatives and the General Electric Company. After a final test design was agreed upon, it was presented to the Integrated Safeguards Experiment - Management Team la combination of both General Electric and Integrated Safeguards Experiment personnel) for final evaluation and approval. A summary of the test designs prepared during the reporting period follows:

a. Task 2A - Fabrication Campaign Material Balance. This test design, as approved for the second of three campaigns, included a summary of processing data and measurements required for material balance calculations. In addition to the routine production measurements, each stream of material will be measured by nondestructive assay techniques developed during the Plant Instrumentation Program (PIP). Several of the processing data sheets were modified as a result of the information and experience gained during ISE Campaiagn 1.

b. Task 2E - Weight Loss by Unit Processing Operation. A revised test design was prepared for material balances for four specific processing operations. Each material stream will be measured for plutonium content. In addition, the impurity content of streams which might be involved in a chemical change will be measured. Each processing operation would be repeated three times to obtain information on the reproducibility of the measurements.

c. Task 2G - Accuracy and Precision Data. The purpose of this test design was to establish guide lines for the preparation of a nonproprietary report of the measurements, both chemical and nondestructive assay techniques used in the ISEs. This report on accuracy and precision data will be useful in disseminating information and experience gained during this experiment to the nuclear industry.

\section{TASK 2. EXPERIMENTAL TESTING}

\section{A. TASK 2A. FABRICATION CAMPAIGN MATERIAL BALANCES - ISE CAMPAIGN 1}

1. General

The fabrication of 28 fuel rods for the Edison Electrical Institute - General Electric Company Program for Utilization of Plutonium in Boiling Water Reactors - Phase II was completed during the reporting period. All required processing data resulting from these rods were transmitted to the Integrated Safeguards Experiment - Technical Representatives. The final material balance calculations are in process. However, a trial material balance has been completed.

\section{Fabrication and Processing Data}

All fabrication information and processing data that pertain to material balance accounting were transmitted to the Integrated Safeguards Experiment - Technical Representatives. The following is a summary of the information transmitted during the reporting period; details of much of this material are General Electric Company Proprietary and limited in distribution by contractual agreement:

a. Process Operating Instructions. New or revised operating instruction either tentative or final developed during the reporting period.

b. Transfer Records (CLA Inventory sheets). Records of all processing line box-to-box transfers of Special Nuclear Material.

c. Weight Gain Experiment. A report on the weight gain (moisture absorption) observed for the feed material.

d. Batch Makeup Records. Blending recurds for the final two master blends. 
e. Travel Cards. Loading records for the 28 fuel rods containing mixed uranium-plutonium oxide.

f. Processing Records. Records of the weight of material accumulated in each vacuum cleaner bag and filter assemblies in the processing line.

g. Analytical Sheets. Sample calculation sheet for plutonium and uranium determinations.

h. Cleanout Summary. An inventory of the Special Nuclear Material remaining in the glove box line after the completion of processing.

i. Analytical Results. The analytical results for plutonium content (plutonium-to-oxide ratio), oxygen-to-metal ratio, and impurities of each master blend.

j. Standardization Data. Data for plutonium, uranium, iron, and oxygen-to-metal ratio standardizations as well as information on daily balance variation.

k. Nuclear Account Location Reports. Machine generated reports on the location of all Special Nuclear Material in the processing line. This report was operational near the end of ISE Campaign 1.

\section{Measure Summary}

Many types of measurements were made on the material streams in ISE Campaign 1. These measurements include chemical determinations for uranium and plutonium as well as nondestructive assay measures accomplished by replacement calorimetry, neutron counting, or gamma scanning. A summary of the number and type of measurements made on each stream is presented in Table 3. The measurements listed in Table 3 relate to the actual stream measured. However, the chemical assay measurements from one stream may define several others, (i.e., the plutonium values for the completed rods, sintered recycle material, and some scrap were obtained from the production samples).

TABLE 3. ISE Campaign 1 - Measurement Summary

\begin{tabular}{|c|c|c|c|c|}
\hline & \multicolumn{4}{|c|}{ Number of Individual Measurement Determinations } \\
\hline & $\begin{array}{l}\text { Chemical } \\
\text { Assay }\end{array}$ & Calorimetry & $\begin{array}{c}\text { Neutron } \\
\text { Counting }\end{array}$ & $\begin{array}{l}\text { Gamma } \\
\text { Scanning }\end{array}$ \\
\hline Plutonia Feed & $5^{(a)}$ & 22 & - & - \\
\hline 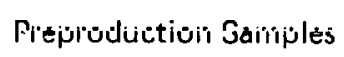 & $30^{(\mathrm{a})}$ & - & - & - \\
\hline Production Samples & $52^{(a)}$ & 25 & - & - \\
\hline Scrap and Recycle. & - & - & 34 & - \\
\hline Discards & - & - & 67 & 20 \\
\hline Completed Rods & - & - & - & $28^{(c)}$ \\
\hline Special Samples & $26^{(b)}$ & - & 40 & - \\
\hline
\end{tabular}

(a) Values used in trial material balances, Table 8

(b) Performed by New Brunswick Laboratory

(c) Not completed

\section{Error Analysis - Plutonium Determination}

The chemical assay measurements for plutonium content were obtained by a coulometric titration technique. The variation observed within a group of samples from one master blend was attributed to the following potential errors: (a) material heterogeneities, (b) sampling (c) sample preparation, (d) sample dissolution, (e) valence adjustment, and (I) coulometric uncertainty. In an attempt to define the magnitude of the coulometric uncertainty. the errors 
associated with each operation in the coulometric titration were propagated. The propagation was performed for 13 production samples. from one master blend of material. The resultant average coulometric uncertainty was $0.31 \%$ (coefficient of variation at one sigma). This was a factor of three smaller than the total variation obtained for the 13 samples, $\mathbf{0 . 9 3} \%$ (coefficient of variation at one sigma). The coulometric uncertainty was a significant part of the error in the determination of the plutonium content, however, it was not the only error involved. Since all the master blends in this campaign were of comparable plutonium content and the same sampling and analysis techniques were used on each, the coulometric uncertainty should remain nearly constant at $0.30 \%$ (coefficient of variation at one sigma).

A comparison of the variation (Table 4) for the master blends in this campaign indicated a range from 0.64 to $1.57 \%$ (coefficient of variation of one sigma). Master Blend (MB) 4 was intentionally blended twice as long as the other three. The extra blending may explain the smaller variation in plutonium content observed for this master blend.

TABLE 4. ISE Campaign 1 - Chemical Assay Summary (Pu: $\mathrm{MO}_{2}$ for production samples)

\begin{tabular}{lllllc} 
& \multicolumn{2}{c}{ Enrichment 1 } & & \multicolumn{2}{c}{ Enrichment 2 } \\
\cline { 2 - 3 } & Blend 1 & Blend 2 & & Blend 3 & Blend 4 \\
Master Blend Identity & M0094 & M0095 & & M0096 & M0098 \\
Sample Number & 13 & 12 & & 14 & 14 \\
Average Pu Content $(\mathrm{gm} / \mathrm{gm})$ & 0.0355 & 0.0354 & & 0.0342 & 0.0344 \\
Standard Deviation $(\mathrm{gm} / \mathrm{gm})$ & 0.00033 & 0.00056 & 0.00031 & 0.00022 \\
Coefficient of Variation (\%) & 0.93 & 1.57 & & 0.90 & 0.64 \\
Standard Error of Mean $(\mathrm{gm} / \mathrm{gm})$ & 0.00009 & 0.00016 & & 0.00008 & 0.00006
\end{tabular}

\section{Analytical Comparison}

Sintered samples from the four master blends in ISE Campaign 1 as well as green samples from MB 4 were sent to New Brunswick Laboratory for plutonium content analysis. A one-way analysis of variance for the sintered samples indicated a significant bias between New Brunswick and General Electric data with the latter being low by $0.80 \%$ (relative) on the average (Table 5). The green samples were not included in this analysis because variation in relative humidity affects the sample weight and introduces a bias in the plutonium content determination. There was no significant difference between the New Brunswick and General Electric analysis for MB 1, 3, and 4. However, MB 2 analyses viere differeint at the $95 \%$ signilicance lèvel.

TABLE 5. ISE Campaign 1 - Analytical Comparison (Chemical Assay - Pu: $\mathrm{Mo}_{2}, \mathrm{gm} / \mathrm{gm}$ )

\begin{tabular}{|c|c|c|c|c|c|c|c|}
\hline \multirow{2}{*}{ Identity } & \multirow[b]{2}{*}{ Material Type } & \multicolumn{3}{|c|}{ General Electric $^{(a)}$} & \multicolumn{3}{|c|}{ New Brunswick ${ }^{(b)}$} \\
\hline & & $\underline{\bar{x}}$ & $\underline{\mathrm{n}}$ & $\underline{\underline{s}}$ & $\underline{\bar{x}}$ & $\underline{\mathrm{n}}$ & $\underline{s}$ \\
\hline M0098 & Green Powder & 0.0337 & 3 & 0.00020 & - & - & - \\
\hline M0098E & & - & - & - & $0 . \dot{3} 336$ & 5 & 0.00013 \\
\hline M0094) & & 0.0355 & 13 & 0.00033 & 0.0356 & 4 & 0.00017 \\
\hline M0095 & & 0.0354 & 12 & 0.00056 & 0.0362 & 6 & 0.00020 \\
\hline M0096 & Sintered Pellet & 0.0342 & 11 & 0.00031 & 0.0342 & 3 & 0.00012 \\
\hline M0098) & & 0.0344 & 14 & 0.00022 & 0.0345 & 3 & 0.00026 \\
\hline
\end{tabular}

(a) Coulometric Titration

(b) 'Potentiometric Titration 


\section{Feed Measurements}

The same plutonia feed lot was utilized for historical Campaign A and ISE Campaign 1. Since desired safeguards control cannot be applied to plutonium fuels if MUF values in excess of $1 \%$ are commonplace in measuring the main product streams (historical campaigns), an attempt was made to obtain better measured values for this feed material. Such values would be required not only for the ISE, but routinely if safeguards for plutonium fuel fabrication is to be accomplished by materials balance accounting. An additional concern to safeguards was the historical practice of using a single value derived from measurements of several cans to characterize an entire feed lot. If this value is an average of several measurements and the material is homogeneous; no difference in the associated measurement error will result from partitioning the material, sampling each partition, and applying that average value to the partitioned quantity. However, if the material is not homogeneous, the accuracy of the measurements for each partition will differ and result in a larger error on the over-all average. Processing experience as well as feed lot history indicates the material in each can may not be identical in plutonium content because of moisture absorption.

Because of concern with the feed measurement as well as the requirement that the ISE campaigns generate material balances completely closed by measurement, chemical analyses were made of the remainder of the plutonia.feed lot to be used in ISE Campaign 1. These measured results are shown in measurements 3 through. 6 given in Table 6 . Measurements 3 and 4 were from a composite sample obtained from four of seven feed cans, replicated three times and averaged. Measurement 5 consists of the average of four samples, one each from four of the seven cans in the feed lot. The individual values of these measurements are shown in Table 7.

Three samples of the remaining feed were sent to New Brunswick Laboratory for analysis. The value shown as measurement 7 was an average of the determinations for these samples. The very large difference between this value and that of the other chemical determinations occurred because New Brunswick Laboratory was not instructed to dry the sample before making the analyses. These analyses as well as the differences in the feed measurements indicate a need for a standard sampling procedure for plutonia.

TABLE 6. ISE Campaign 1 - Plutonia Feed Measurements

\section{Measurement}

1. $\mathrm{ARHCO}^{(\mathrm{b})}(1969)$

2. $G E^{(d)}$

3. $\mathrm{GE}$

4. $G E$

5. GE

6. $\mathrm{GE}$

7. NBL

8. $\mathrm{GE}$

9. GE

(1970)
Measurement Method

Potentiometric

Amperometry (composite)

Coulometry (compoșite)

Coulometry (composite)

Coulometry (4 samples)

Coulometry (4 samples)

Potentiometric (3 samples)

Calorimetry

(1969 ARHCO isotopic values)

Calorimetry

(1970 GE isotopic values)

Pu Content,
87.72
86.39
$87.27^{(e)}$
$85.57^{(f)}$
$86.99^{(e)}$
$85.18^{(f)}$
$84.89^{(f)}$
$87.94^{(l)}$
$87.23^{(h)}$

$$
\underline{P u} \cdot g^{(a)}
$$

Difference, \%

$$
5882.3^{(c)} \text {. }
$$$$
5798.0
$$$$
-1.44
$$$$
5857.0
$$$$
-0.43
$$

5838.2$$
-(g)
$$

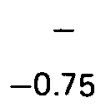

$-0.75$

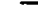

5901.7

$+0.33$

5854.5
(a) Net weight plutonia 6711.3 grams
(b) Atlantic Richfield Hanford Company
(c) Includes correction for analytical bias
(d) General Electric

(e) Samples dried before analysis

(f) Samples analyzed as-received from Plutonium Laboratory. Values low because of moisture pickup.

(g) Grams plutonium not calculated because plutonia.weights after moisture pickup were not available.

(h) Value calculated from net weight and weight of plutonium. 
TAELE 7. ISE Campaign 1 - Individual Feed Can Measurements

\begin{tabular}{|c|c|c|c|c|c|c|c|c|c|c|}
\hline \multirow[b]{3}{*}{ Feed Can } & \multirow{3}{*}{$\begin{array}{c}\text { Net } \\
\text { Weight, } \\
\text { gm (a) } \\
\end{array}$} & \multicolumn{2}{|c|}{ Potentiometric-ARHCO ${ }^{(b)}$} & \multicolumn{4}{|c|}{ Coulometry-GE ${ }^{(c)}$} & \multicolumn{3}{|c|}{ Calorimetry-GE ${ }^{(c)}$} \\
\hline & & \multirow[b]{2}{*}{ PL Assay $\stackrel{\%}{\%}$} & \multirow[b]{2}{*}{$\underline{P u, g m}$} & \multirow{2}{*}{$\begin{array}{c}\text { No. of } \\
\text { Samples } \\
\end{array}$} & \multicolumn{2}{|c|}{ Pu Content \% . A } & \multirow[b]{2}{*}{$\underline{P_{u, g m}(d)}$} & \multirow{2}{*}{$\begin{array}{c}\text { No. of } \\
\text { Analysis }\end{array}$} & \multicolumn{2}{|c|}{$\mathrm{Pu}, \mathrm{g}$} \\
\hline & & & & & As-Received & Dried $^{(\mathrm{e})}$ & & & ARHCO-I sotopic & GE-Isotopic \\
\hline A & 554.7 & - & 486.58 & $\div$ & - & - & 483.20 & 6 & 486.48 & 489.48 \\
\hline $\mathrm{B}$ & 664.0 & - & 582.46 & 1 & 83.90 & 86.86 & 578.41 & 1 & 586.56 & 579.55 \\
\hline C & 939.7 & - & 824.30 & 1 & 85.47 & 86.44 & 818.57 & 1 & $819.33^{(f)}$ & $816.63^{(f)}$ \\
\hline $\mathrm{D}$ & $1109.8^{(g)}$ & - & 973.52 & - & - & - & 966.75 & 9 & 979.17 & 968.67 \\
\hline$E$ & 1122.8 & - & 984.92 & 1 & 85.49 & 87.59 & 978.07 & 1 & 991.86 & 977.87 \\
\hline$F$ & 1163.9 & - & 1020.97 & - & - & - & 1013.87 & 2 & 1020.88 & 1012.42 \\
\hline G & 1163.8 & - & 1020.89 & 1 & 85.87 & 87.08 & 1013.78 & 2 & $1009.96^{(f)}$ & $1017.36^{(f)}$ \\
\hline Composite ${ }^{(h)}$ & - & 87.72 & - & 3 & $\begin{array}{l}85.54 \\
85.47 \\
85.69\end{array}$ & $\begin{array}{l}87.25 \\
87.39 \\
87.17\end{array}$ & - & - & - & - \\
\hline
\end{tabular}

(a) Net weights obtained before sampl ng.

(e) Dried at 200 to $300^{\circ} \mathrm{C}$

(b) Atlantic Richfield Hanford Company

(f) 3.7-gram sample taken before calorimetry measurements

(c) General Electric

(d) Based on average of dried values from all feed cans.

(g) Vendors weight since this feed can was not used during processing

(h) Composed of $\sim 3.7$ grams samples from feed cans B, C, E, and G. 
The calorimetry instrumentation associated with the Plant Instrumentation Program was utilized to measure the ISE Campaign 1 feed material. These measurements were made and the value of feed material calculated on two bases, the isotopic composition (a) supplied by the vendor in 1969 and (b) determined by General Electric in 1970*. These values are shown in Table 6 as measurements 8 and 9 and more detailed data are shown in Table 7. The reproducibility of the calorimetry measurements on plutonia feed was impressive. However, the accuracy is dependent upon the errors associated with the plutonium isotopic composition.

It was difficult to select which value should be assigned to the feed material in calculating the material balance for ISE Campaign 1. An average of all the analyses made for dried plutonium was used as the plutonium content of the feed material. This value for feed was support by calorimetry measurements based on General Electric isotopic determinations (chemical assay $\doteq 5847.3$ grams plutonium and calorimetry -5854.5 grams plutonium). The use of the synthetically obtained value for plutonium content may result in a MUF contribution before the start of fuel processing.

\section{TRIAL MATERIAL BALANCE}

Since analysis of all the nondestructive assay measurements were not completed during the reporting period, trial material balances were prepared from the available data. The format of these balances was similar to the historical balances, however only total oxide streams which were measured (weighed) were included. In addition, the plutonium and uranium balances were obtained by applying the appropriate measured metal-to-oxide ratio to the total oxide weights. Any unmeasured material stream was considered as MUF. A trial material balance was prepared for both enrichments 1 and 2, 3.54 and 3.42\% plutonium content, respectively. Each enrichment consisted of two master blends which were treated separately and combined for the trial balance.

The first step in preparing the trial material balance was to obtain a total oxide balance for each enrichment. The individual oxide weights were separated into sub-groups by metal-to-oxide ratio, then summed, and multiplied by the appropriate metal-to-oxide concentration factor to obtain the uranium and plutonium balances. Where possible the total oxide values were summed by master blend: However, normal processing procedure requires the summation of some values by enrichment. It should be noted that the trial balances depart from a true measured balance as follows:

1. The metal-to-oxide ratios obtained from blended powders (pre-production samples) were used to characterize all unsintered material, i,e, green scrap and green process losses.

2. The metal-to-oxide ratios obtained from sintered pellets (production samples) were used to characterize all sintered material, i.e., sintered scrap, sintered process losses, and product.

3. The total oxide weights for process losses (vacuum cleaner bags and prefilters), part of the green scrap and the dirty sintered scrap; may include some material other than SNM.

4. A theoretical oxide-to-metal ratio was used to obtain the uranium content of the feed.

A trial material balances for total oxide, plutonium, and uranium are shown in Table 8 . The trial material balances resulted in MUF values of -0.06 and $0.01 \%$ for total oxide; 1.40 and $1.71 \%$ for plutonium; and 0.55 and $0.92 \%$ for uranium for enrichments 1 and 2 respectively. The limits of error for each stream were combined such that the error in the appropriate metal-to-oxide factor was propagated with the error obtained from the summation of weights of the same concentration. The limit of error calculations for enrichment 1 and 2 are presented in Table 9 . The MUF value for total oxide and plutonium were larger than the associated limit of error. The addition of the nondestructive assay data to these balances may reduce the MUF value (account for more material) as well as increase its limit of error (addtional measurements included in balance).

Since the total oxide MUF was much smaller than the plutonium MUF, the plutonium loss cannot be explained by loss of mixed uranium-plutonium oxide during processing. These losses indicated the plutonium MUF resulted from either a plutonia loss, analytical bias, or incorrect input feed measurements. In view of the difficulty encountered with the teed measurements, the latter appears to be the more plausible explanation.

*Plant Instrumentațion Program, Serond nuarterly Report, itly 1970 to September 1870, GE ^P 121113. 
TABLE 8. ISE Campaign $i$ - Material Balance

Enrichment 1 - 3.54\% Pu Content, \%

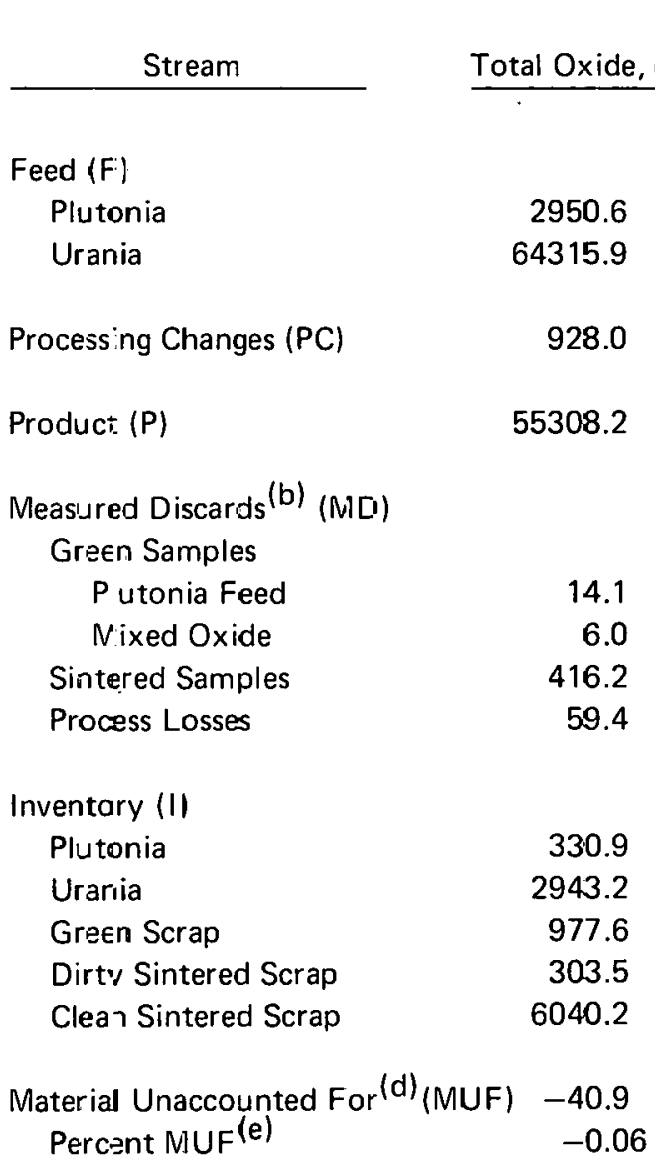

Enrichment 2-3.42\% Pu Content, \%

\begin{tabular}{|c|c|c|c|}
\hline Stream & Total Oxide, gm & $\mathrm{Pu}, \mathrm{gm}$ & U. gm \\
\hline \multicolumn{4}{|l|}{ Feed $(F)$} \\
\hline Plutonia & 2988.5 & 2603.9 & $-\quad<a$ \\
\hline Urania & 72339.9 & - & $63297.1^{\text {ld }}$ \\
\hline Processing Changes (PC) & 988.7 & - & - \\
\hline Product $(\mathrm{P})$ & 61249.0 & 2095.6 & 51724.8 \\
\hline \multicolumn{4}{|l|}{ Measured Discards $^{(b)}(\mathrm{MD})$} \\
\hline \multicolumn{4}{|l|}{ Green Samples } \\
\hline Plutonia Feed & 14.8 & 12.9 & - \\
\hline Mixed Oxide & 11.3 & 0.5 & 9.5 \\
\hline Sintered Samples & 403.8 & 13.8 & 341.0 \\
\hline Process Losses & 99.1 & 3.4 & 83.4 \\
\hline \multicolumn{4}{|l|}{ Inventory (I) } \\
\hline Plutonia & 135.7 & $118.2^{(\mathrm{c})}$ & - \\
\hline Urania & 3171.3 & - & 2774.9 \\
\hline Green Scrap & 3541.6 & 120.1 & 2964.3 \\
\hline Dirty Sintered Scrap & 229.4 & 7.9 & 193.7 \\
\hline Clean Sintered Scrap & 5475.2 & 187.0 & 4623.8 \\
\hline Material Unaccounted For ${ }^{(d)}$ & IUF) & 44.5 & 581.7 \\
\hline Percent MUF ${ }^{(e)}$ & 0.01 & 1.71 & 0.92 \\
\hline
\end{tabular}

(a) Based on theoretical uranium-to-oxide values

(b.) Excludes processing waste awaiting nondestructive assay

(c) Corrected for moisture equilibration

(d) M.UF $=F-(P C+P+M D+1)$ for appropriate va lues

(E) Based on input 
TABLE 9. ISE Campaign 1 - Limits of Error ${ }^{(a)}$

\begin{tabular}{|c|c|c|c|c|c|c|c|c|c|c|c|c|c|}
\hline \multicolumn{7}{|c|}{ Enrichment $1-3.54 \%$ Pu Content, $\%$} & \multicolumn{7}{|c|}{ Enrichment $2-3.42 \%$ Pu Content, \% } \\
\hline \multirow[b]{2}{*}{ Stream } & \multicolumn{2}{|c|}{ Total Oxide } & \multicolumn{2}{|c|}{ Plutonium } & \multicolumn{2}{|c|}{ Uranium } & \multirow{2}{*}{ Stream } & \multicolumn{2}{|c|}{ Total Oxide } & \multicolumn{2}{|c|}{ Plutonium } & \multicolumn{2}{|c|}{ Uranium } \\
\hline & (gm) & $(\%)$ & $(\mathrm{gm})$. & $(\%)$ & $(\mathrm{gm})$ & $(\%)$ & & $(\mathrm{gm})$ & $(\%)$ & $(g m)$ & $(\%)$ & $(\mathrm{gm})$ & $(\%)$ \\
\hline Feed & & & & & & & Feed & & & & & & \\
\hline Plutonia & 0.52 & 0.02 & 6.10 & 0.24 & - & - & Plutonia & 0.50 & 0.02 & 6.19 & 0.24 & - & - \\
\hline Urania & 0.76 & 0.00 & - & - & $569.76^{(b)}$. & 1.00 & Urania & 0.81 & 0.00 & - & - & $632.98^{(b)}$ & 1.00 \\
\hline Prcduct & 1.04 & 0.00 & 8.61 & C. 44 & 93.70 & 0.20 & Product & 0.92 & 0.00 & 5.40 & 0.26 & 73.68 & 0.14 \\
\hline Measured Discards & & & & & & & Measured Discards & & & & & & \\
\hline Green Samples & & & & & & & Green Samples & r & & & & & \\
\hline Plutonia & 0.24 & 1.70 & $0.2 i$ & 1.72 & - & - & Plutonia & 0.49 & 3.31 & 0.42 & 3.26 & - & - \\
\hline Mixed Oxide & 0.47 & 7.83 & 0.02 & $1 \mathrm{C.00}$ & 0.38 & 7.36 & Mixed Oxide & 0.78 & 6.90 & 0.02 & 4.00 & 0.65 & 6.84 \\
\hline Sintered Samples & 1.04 & 0.25 & 0.08 & 0.54 & 1.12 & 0.32 & Sintered Samples & 0.96 & 0.24 & 0.05 & 0.36 & 0.94 & 0.28 \\
\hline Process Losses & 0.46 & 0.77 & 0.03 & 1.43 & 0.42 & 0.84 & Process Losses & 0.55 & 0.55 & 0.02 & 0.59 & 0.48 & 0.58 \\
\hline Inventory & & & & & & & Inventory & & & & & & \\
\hline Plutonia & 0.23 & 0.07 & $0.71^{:}$ & 0.25 & - & - & Plutonia & 0.19 & 0.14 & 0.33 & 0.28 & - & - \\
\hline Urania & 0.20 & 0.01 & - & - & $25.76^{(b)}$ & 1.00 & Urania & 0.20 & 0.01 & - & - & $27.74^{(b)}$ & 1.00 \\
\hline Green Scrap & 0.53 & 0.05 & 0.54 & 1.58 & 0.55 & 0.07 & Green Scrap & 0.56 & 0.02 & 0.90 & 0.75 & 12.05 & 0.41 \\
\hline Dirty Sintered Scrap & 0.24 & 0.08 & 0.04 & 0.37 & 0.56 & 0.22 & Dirty Sintered Scrap & 0.20 & 0.09 & 0.02 & 0.25 & 0.32 & 0.16 \\
\hline Clean Sin-ered Scrap & 0.55 & 0.01 & 0.85 & 0.40 & 10.24 & 0.20 & Clean Sintered Scrap & 0.55 & 0.01 & 0.66 & 0.35 & 6.60 & 0.14 \\
\hline Màterial Unaccounted For ${ }^{(c)}$ & 2.02 & & 10.78 & & 542.10 & & Material Unaccounted For ${ }^{(c)}$ & 2.10 & $\sim$ & 7.16 & & 607.36 & \\
\hline & & (a) & All quanti & ties are & wo sigma & & & & & & & & \\
\hline & & (b) & Assumed & error on & minal uran & ium as: & $\pm 0.5 \%$ relative & & & & & & \\
\hline & & (c) & Limits of & error co & cted for col & Jarianc & $\mathrm{ns}$ included in the body of the & & & & & & \\
\hline
\end{tabular}


The uranium MUF was smaller than the associated limit of error. The use of a theoretically determined metal-to-oxide value as well as an assumed error for the uranium content of the feed appears to overshadow the usefulness of the balance.

\section{Total Oxide Balances}

The transfer of materia! to and from a Criticality Limit Area (CLA) in the processing line (see Figure 1) was manually recorded on CLA Inventory sheets and the running sum of metal and fissile weights maintained within the CLA. At any one time, material from several different master blends can be within the same CLA (usually a glove box) as long as its criticality limit is not exceeded. The information recorded on the CLA Inventory sheets has been used to obtain a total oxide weight balances on each CLA involved in ISE Campaign 1.

A computerized version of the CLA Inventory material transfer records has been developed and implemented but was not available for the entire ISE Campaign 1. The total oxide weight balances (Table 10) were calculated manually. These calculations were made in a format similar to that used in the computer system. Therefore, these balances represent the book inventory of each master blend within a CLA at the conclusion of ISE Campaign 1. These balances can eventually be compared with the book inventory of each master blend which was generated by the computerized system.

Except for master blend makeup in Box 37 and rod loadings in Box 43, the data recorded on the CLA Inventory sheets were used as input for the total oxide balance calculations. The quantity measured at the start of the process (Box 37) was the sum of the weights of plutonia and urania used in the master blend makeup. Since a data acquisition subprogram of the Mechanized Accountability and Criticality System provides for special entries regarding master blend makeup, the recording forms which would have provided the master blend make-up data to the computerized system were used directly for the total oxide weight balances. In Box 43, some rods were loaded with product from more than a single master blend. The computerized system accounts for rod loadings by master blend with a transaction designated as rod makeup. The rod make-up sheets have been used to perform manually the allocation of rod loadings to master blends for the total oxide balance.

The examination of the total oxide balances indicated several values which were inconsistent with processing experience. In each case, the manual transfer records were re-examined to determine if an error had been made during manual processing. The first inconsistency was observed in the Box 38 balance (Table 10B). The total oxide balance for M0094 indicated a net material gain of 366.0 grams. No apparent explanation was found for this inconsistency. The most probable cause was either an erroneous or deleted transfer entry. Another inconsistency was found in the Box 39 , 40, and 41 balance (Table 10C). These balances indicated that M0096 exhibited a material gain of 167.3 grams Processing experience indicated a weight loss of about $1.5 \%$ should be expected for these boxes, i.e., sintering loss. Examination of the transfer records uncovered a double entry which affected both the Box 39,40 , and 41 and the Box 42 balances. The corrected balances are shown in Tables 10D and 10F.

The material for the second master blend of each plutonium enrichment (M0095 and M0097-8) exhibited a material gain. This gain resulted from the processing practice of cleaning the glove boxes only after completing an enrichment. This resulted in cross mixing of the scrap.

The following statements can be made upon examination of each individual bulk oxide balance:

1. Box 37 (Table 10A). The over-all material gain in this glove box was a result of moisture and oxygen pickup during blending.

2. Box 38 (Table 10B). A material gain with no assignable cause.

3. Boxes 39, 40, and 41 (Table 10D). The large material loss was a result of sintering the mixed (uranium-plutonium) oxide in a reducing atmosphere, i.e., drives off moisture, oxygen, and other volatiles.

4. Box 42 (Table 10F) and Box 43 (Table 10G). These individual total oxide balances resulted in either a small material Inss or gain. These variations appear to result from normal processing operations. 
TABLE 10. Box and Batch Balance

A. $\quad$ Box 37

\begin{tabular}{|c|c|c|c|c|c|c|c|c|}
\hline \multirow{2}{*}{$\begin{array}{l}\text { Material } \\
\text { Identity } \\
\end{array}$} & \multirow[b]{2}{*}{$\underline{\ln }$} & \multirow[b]{2}{*}{$\underline{\text { Out }}^{(a)}$} & \multirow[b]{2}{*}{ Sample $^{(b)}$} & \multirow{2}{*}{$\begin{array}{l}\text { Clean } \\
\text { Scrap }\end{array}$} & \multirow{2}{*}{$\begin{array}{l}\text { Dirty } \\
\text { Scrap }\end{array}$} & \multirow[b]{2}{*}{ Waste } & \multicolumn{2}{|c|}{ Oxide Balance } \\
\hline & & & & & & & Blend & Enrichment \\
\hline M0094 & 32401.8 & 31791.2 & 3.0 & - & 401.8 & 15.6 & 190.2 & - \\
\hline M0095 & 32173.0 & 31905.6 & 3.0 & 236.8 & 215.3 & 20.3 & -208.0 & - \\
\hline Enrichment 1 & 64574.8 & 63696.8 & 6.0 & 236.8 & 617.1 & 35.9 & - & -17.8 \\
\hline M0096 & 32586.8 & 31881.4 & 5.0 & - & 604.8 & 2.3 & 93.3 & - \\
\hline M0097-8 & 42763.4 & 39995.5 & 11.3 & 1994.7 & 864.9 & 25.0 & -128.0 & - \\
\hline Enrichment 2 & 75350.2 & 71876.9 & 16.3 & 1994.7 & 1469.7 & 27.3 & - & -34.7 \\
\hline ISE Campaign 1 & - & - & - & - & - & - & - & -52.5 \\
\hline B. $\quad$ Bo 38 & & & & & & & & \\
\hline M0094 & 32257.7 & 32608.8 & - & - & - & 14.9 & -366.0 & - \\
\hline M0095 & 32408.6 & 32439.2 & - & - & - & 19.9 & -50.5 & - \\
\hline Enrichment 1 & .64666 .3 & 65048.0 & - & - & - & 34.8 & - & -416.5 \\
\hline M0096 & 31882.4 & 31826.5 & - & - & - & 3.1 & 52.8 & - \\
\hline M0097-8 & 40133.5 & 40143.1 & - & - & - & 31.6 & -41.2 & - \\
\hline Enrichment 2 & 72015.9 & 71969.6 & - & - & - & 34.7 & - & 11.6 \\
\hline ISE Campaign 1 & - & - & - & - & - & - & - & -404.9 \\
\hline C. Boxes 39,4 & and 41 & & . & & & & $\cdot$ & \\
\hline MoU94 & 36732.4 & 35583.3 & - & - & 40.5 & 0.9 & 1107.7 & - \\
\hline M0095 & 32858.0 & 32422.4 & - & - & 83.0 & 9.3 & 343.3 & - \\
\hline Enrichment 1 & 69590.4 & 68005.7 & - & - & 123.5 & 10.2 & - & 1451.0 \\
\hline M0096 & 31239.7 & 31402.0 & - & -- & - & 5.0 & -167.3 & - \\
\hline M0097.8 & 45154.4 & 44519.7 & - & - & 74.2 & 67.4 & 193.1 & \\
\hline Enrichment 2 & 76394.1 & 75921.7 & - & - & 74.2 & 72.4 & - & 325.8 \\
\hline ISE Campaign 1 & - & - & - & - & - & - & - & 1776.8 \\
\hline D. Boxes 39, 4 & and 41 (co & rected for & dundant ent & & & & & \\
\hline M0094 & 36732.4 & 35583.3 & - & - & 40.5 & 0.9 & 1107.7 & - \\
\hline M0095 & 32858.0 & 32422.4 & - & - & 83.0 & 9.3 & 343.3 & - \\
\hline Enrichment 1 & 69590.4 & 68005.7 & - & - & 123.5 & 10.2 & - & 145.1 .0 \\
\hline M0096 & 31239.7 & 30627.1 & - & - & - & 5.0 & 607.6 & - \\
\hline M0097-8 & 45154.4 & 44519.7 & - & - & 74.2 & 67.4 & 493.1 & \\
\hline Enrichrnent 2 & 76394.1 & 75146.8 & - & - & 74.2 & 72.4 & - & 1100.7 \\
\hline ISE Campaign 1 & - & - & - & - & - & - & - & 2551.7 \\
\hline
\end{tabular}


TABLE 10. (Continued)

E. $\quad$ Box 42

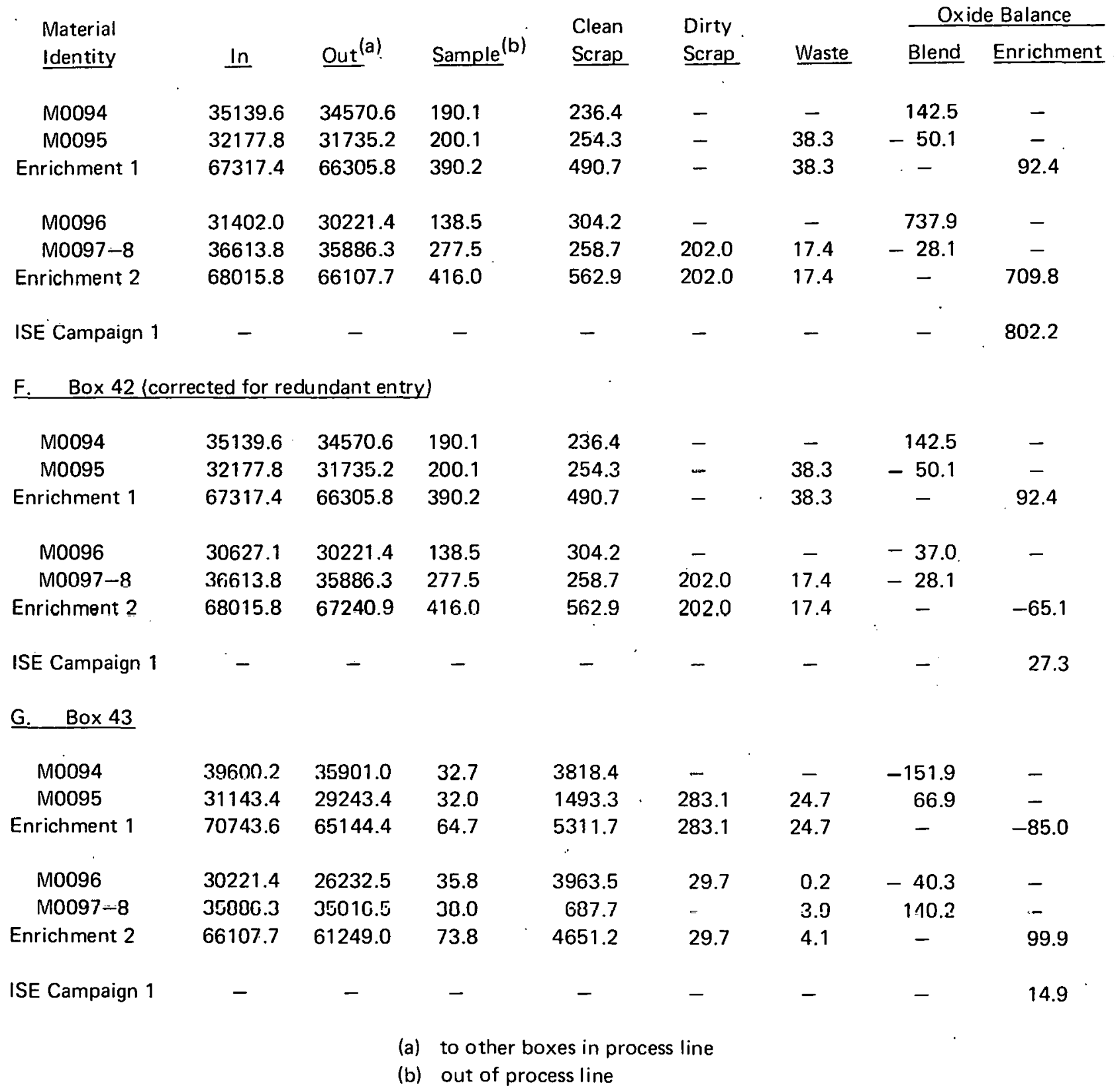




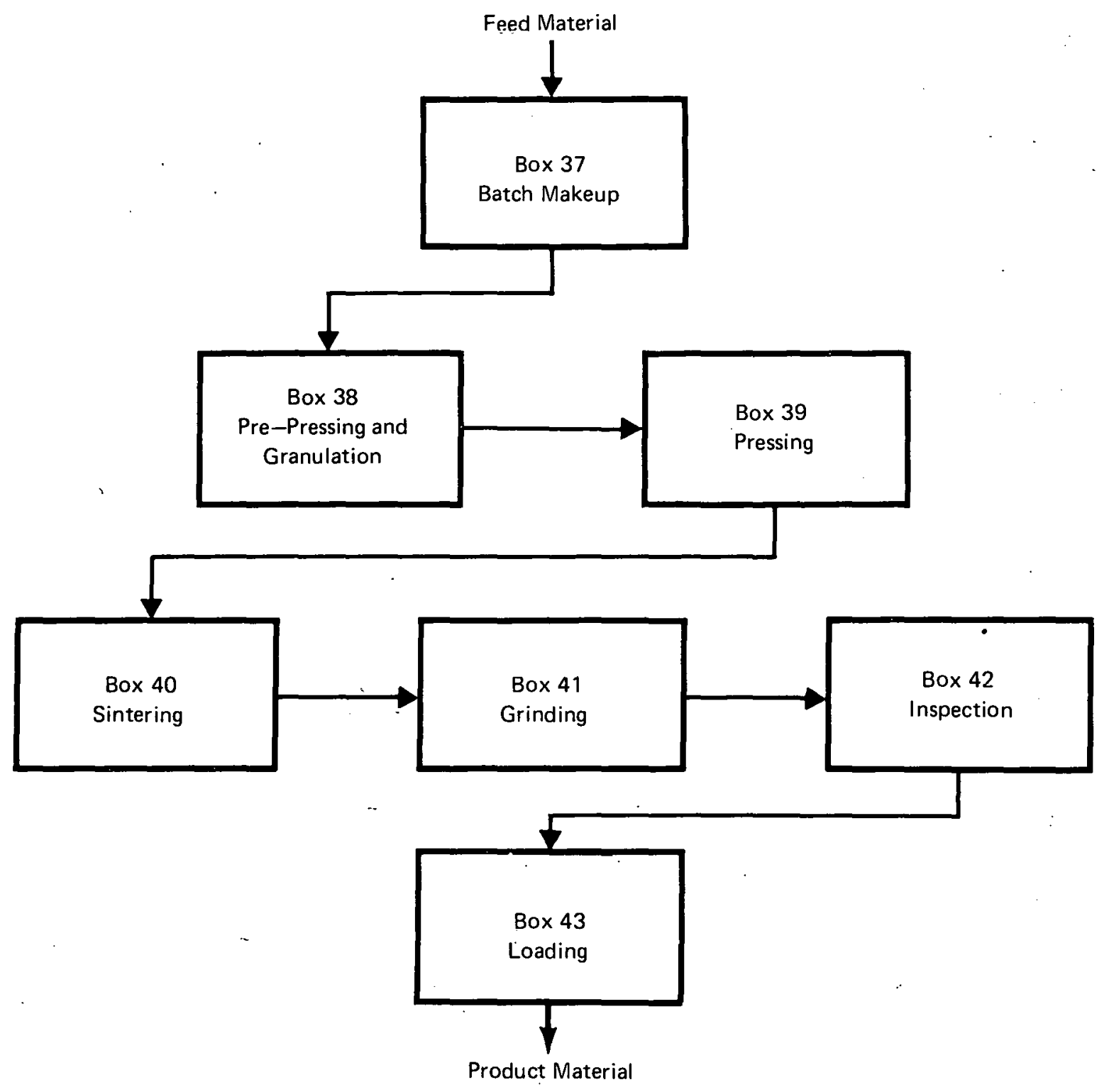

Arrows denote main material flow

FIGURE 1. IȘE PROCESSING LINE 
In the future, these weight balances can be compared with balanices constructed from other sources of data, such as manual transfer records for blend makeup, sintering furnace records, clean-out summaries, and Nuclear Accounting (NAC) location reports.

\section{B. TASK 2A. FABRICATION CAMPAIGN MATERIAL BALANCE - ISE CAMPAIGN 2}

\section{General}

After approval of Task 2A was obtained from the Integrated Safeguards Experiment-Management Team, the Laboratory Plan for ISE Campaign 2 was prepared and implemented in the Plutonium Laboratory. During this campaign, 20 plutonium fuel rods are being fabricated under the joint Edison Electrical Institute - General Electric Company Progaram for Utilization of Plutonium in Boiling Water Reactors - Phase II. ISE Campaign 2 was initiated the last week in October with sampling of the plutonia feed. Fuel processing was started early in November.

\section{Laboratory Plan}

In addition to the fabrication plan required for normal operation, a special laboratory plan was prepared jointly by Integrated Safeguards Experiment - Technical Representatives and General Electric personnel. The laboratory plan provided special forms for recording data applicable to material balance accounting; methods for obtaining and monitoring standardization data, and procedures for packaging material measured nondestructively.

\section{Fabrication and Processing Data}

All fabrication information and processing data available to date which pertains to material balance accounting were transmitted to the Integrated Safeguards Experiment - Technical Representatives. The following is a summary of the information transmitted during the reporting period; details of much of this material are General Electric Company Proprietary and limited in distribution by contractual agreement:

a. Process Operating Instructions. New or revised operating instructions either tentative or final developed during the reporting poriod.

b. Transfer Records (CLA Inventory sheets). Records of all processing line box-to-box transfers of Special Nuclear Material.

c. Batch Makeup Records. Blending records for the two master blends.

d. Processing Records. Records of the weight of material accumulated in each vacuum cleaner bag and filter assemblies in the processing line.

e. Clean-Out Summary. An inventory of the Special Nuclear Material remaining in the glove box line after the completion of processing.

f. Standardization Data. Data for plutonium, uranium, and iron standardizations as well as information on daily balance variation.

g. Analytical Hesults. The calculation and reporting sheets for plutonium content determinations.

h. Processing data. Sintering records which include sintering results as well as grinding information.

i. Sample Log. A record of all samples and sample weights taken during normal processing.

j. NAC Location Reports. Machine generated reports of the location of all Special Nuclear Material in the processing line. 


\section{Feed Measurements}

In an attempt to overcome the problems associated with the feed measurements in both the historical data and ISE Campaign 1, an extensive measurement program was initiated for this feed material. The program includes 93 individual measurements which include chemical assay, replacement calorimetry, and neutron counting. Many of these measurements were replicated determinations on the same material or measurements on split or sampled feed cans. A summary of these measurements is presented in Table 11.

After completion of the nondestructive assay measurements, the feed cans were opened and allowed to reach an equilibrated weight. This equilibration step was undertaken before sampling to eliminate the possibility of nonuniform moisture absorption between the feed cans and samples. The total plutonium received was then obtained from the equilibrated weight and chemical assay, see measurements 2, 3, and 4 in Table 11.

The agreement between these measurements was much better than that observed for ISE Campaign 1. To obtain agreement between chemical assay values for different laboratories, it appears necessary to develop a uniform sampling and analysis method for plutonium.

\section{TASK 2B. DATA HANDLING SYSTEMS}

\section{General}

The General Electric funded programming of the Mechanized Accountability and Criticality System has progressed so that the NAC locations report can be generated routinely. Programming was initiated to change the Chemistry File output so that it can be used to update the measured values in the accounting system.

\section{Mechanized Accountability and Criticality System}

The flow chart shown in Figure 2 illustrates the Mechanized Accountability and Criticality System as of late October. The Raytheon 703 produces a paper tape for each valid Special Nuclear Material transaction generated in the processing line. This paper tape is sent to the General Electric computer center through a time share terminal. During this operation, editing of input data is accomplished through the use of the Text Editor routine. The edited data are stored on a disk file until needed by the NAC program or punched on cards for temporary storage. The Pre-Processor Program reads the transaction records from the disk or card file and prepares a magnetic tape in a format suitable for final processing. Further data editing is possible at this step.

The input for the NAC File Processor consists of the previous inventory (Old Inventory File) and the new transactions from the Pre-Processor. An actual physical inventory may be used as input to the NAC File Processor. The output consists of a tape containing the location of all the Special Nuclear Material packages in the inventory (New Inventory File). Note that on the next processing, this file becomes the previous or old inventory. A magnetic tape History File of all transactions is produced by adding the new transactions to those previously stored. The NAC location report is then written from the Inventory File and shows the location of all items in the processing line by Criticality Limit Area (CLA).

\section{Shemistry File}

Changes in the Chemistry Program have been initiated to provide usable measured values for the NAC location report. In addition, the machine calculated averages and sigma values will be manually screened and used as input for NAC limit of error calculations (see Task $2 F-$ MUF Calculations).

\section{MUF Report}

The report of MUF on a master blend basis is nearing completion. Test cases were operational and minor problems are being resolved before the system can be used in the laboratory. While the calculated limits of error for list items will not be included in the initial reports, weights for total oxide, plutonium metal, uranium metal, and total metal will be identified. The limit of error values will be added when they become available. 
TABLE 11. ISE Campaign 2 Plutonia Feed Measurements

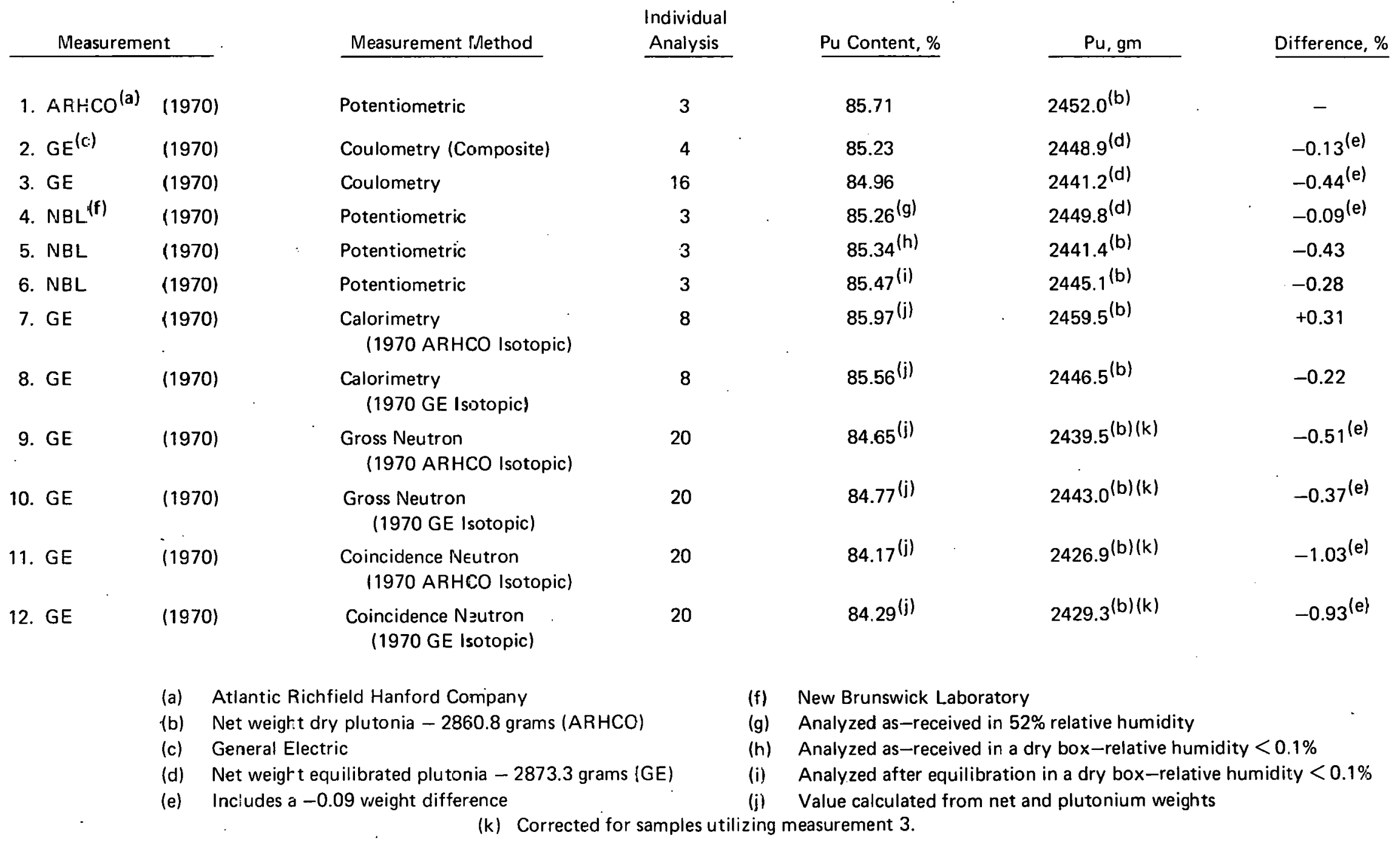




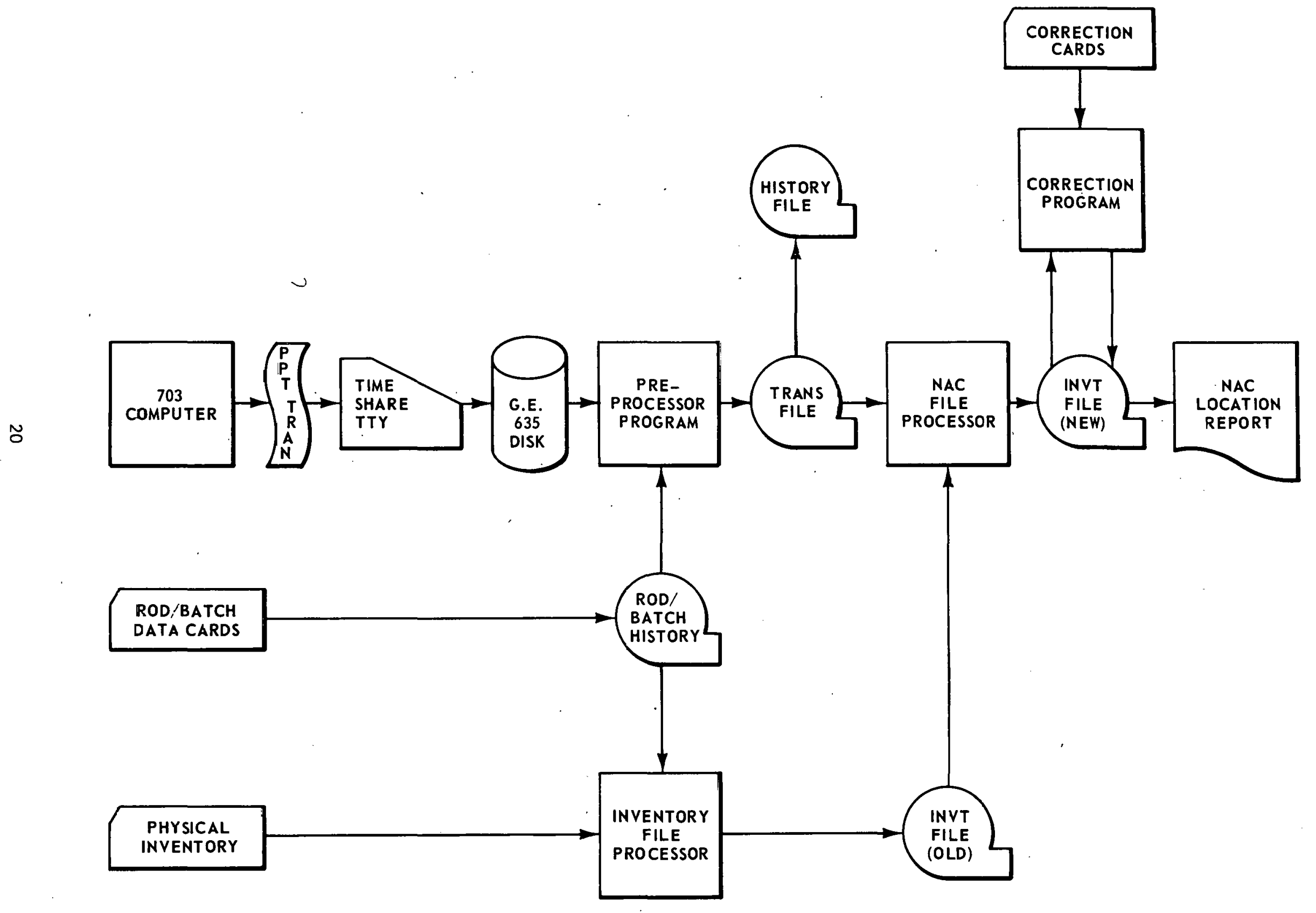




\section{TASK 2D. PROGRAM REVIEW}

Before the start of ISE Campaign 2, a program review was held for the Integrated Safeguards Experiment Management Team. The following topics were discussed at this review:

1. Summary of ISE Campaign 1 data;

2. Acceptance of the following test designs: Task 2A - Fabrication Material Balance - ISE Campaign 2, Task 2F - MUF Calculations, and Task 2G - Accuracy and Precision Report;

3. Deletion of Task 2E - Weight Loss by Unit Operation;

4. Laboratory Plan for Task 2A - Fabrication Material Balarice - ISE Campaign 2;

5. International Atomic Energy Agency participation in the ISE;

6. A review of progress versus expenditure.

\section{E. TASK 2E. WEIGHT LOSS BY UNIT PROCESSING OPERATION}

One of the objectives of the ISE was to identify and to measure previously unmeasured or unidentified processing losses. Task 2E as originally conceived would have weighed sub-groups of in-process material both before and after each sequential operation. By knowing the size and the variability of the measured weight losses efforts can be concentrated better in future campaigns.

The operations of the greatest interest are those spanning the process from initial blending of urania and plutonia to completion of subsequent sintering of mixed uranium-plutonium oxide pellets. In many cases the weight changes of the material are quite misleading. The green mixed uranium-plutonium oxide powder picks up weight, both moisture and oxygen, at various stages during green (unsintered) powder processing. During the sintering process the moisture is removed and the material approaches its stoichiometric composition. An alternative method for close measurement of the weighed flow values of the material was needed. After some joint effort by the Integrated Safeguards Experiment Technical Representatives and General Electric personnel, a revised Task 2E which coupled the weighing of sub-groups of the material into and out of each processing operation was devised. These weighings would be coupled with an anaIytical sample to determine the amount of plutonium transferred with each measurement. It was planned to initiate the revised Task 2E in ISE Campaign 2 based on analytical data from ISE Campaign 1. Under the revised Task 2E, plutonium content values were to be determined for samples of mixed uranium-plutonium oxide material. Only twelve samples of green material, three from each master blend, were analyzed during ISE Campaign 1. Although these subpopulations of three were too small to generate statistics, it was still possible to assess the variation in plutonium content by using the sintered pellet values. Most personnel familiar with the analysis procedure felt that the sintered pellet anaısis variance should be less than that for green powder. The results for each of the master blends sintered are given in Table 4.

The product specifications called for master blends 1 and 2 to be identical as well as master blends 3 and 4 . The means of each of the two palrs of blends are not significantly different nor are the variances of blends 3 and 4 . The ratio test for the variance of blend 2 to blend 1 fails at the $95 \%$ confidence level. The range in the uncertain (one sigma coefficient of variation) of the sintered pellets varied from 0.64 to $1.57 \%$. A value of $1 \%$ as an estimate for sigma seems reasonable and results in a $95 \%$ confidence limit of approximately $2 \%$.

With these results available, the advisability of performing Task $2 \mathrm{E}$ required reassessment. The quantities of material unaccounted for by ordinary process or clean-out measurement techniques would not be large. Therefore, to say anything meaningful about plutonium loss for a unit processing operation under Task $2 \mathrm{E}$, the amount of unidentified oxide losses would have to be large enough so that the plutonium content would exceed the uncertainty in measurement. If, for example, 30 gramis of mixed oxide might not be accounted for in a throughput of 8000 grams, the resultant plutonium loss would be about 0.8 gram (approximately a $2.5 \%$ plutonium content). The limit of error 
based upon measurement would be approximately plus-or-minus 4.4 grams of plutonium which completely over-rides the unaccounted for plutonium. It became clear that the losses were much too small relative to measurement error to run a useful experiment. Consequently, the Integrated Safeguards Experiment-Management Team decided to delete this experiment.

\section{F. TASK 2F. MUF CALCULATIONS}

Development of a simplified model for obtaining the limits of error for MUF has been initiated under General Electric funding for accounting on a master blend-by-master blend basis. The method is based on the material which goes in and out of the process. The MUF calculations involve measuring the amount of (a) incoming material, ' (b) finished product, (c) scrap, and (d) material recovered in cleanup. The value of MUF is then the amount of incoming material minus all the other amounts. The method does not make full use of all the measurements of the material. Certain measurements are ignored entirely and others are not used most efficiently. This is done to simplify the model and the calculation of the limits of error on MUF. In particular, the method uses only measurements that are statistically independent, that is, separate measurements that have statistically independent random errors. Moreover, certain quantities calculated from the measurements are statistically independent since each measurement is used in only one such calculated quantity. Independence of such quantities greatly simplifies the calculation of the limits of error.

\section{MISCELLANEOUS}

\section{A. TRIPS}

E. F. Kurtz visited the United States Atomic Energy Commission Headquarters during September 2-4, 1970, for a Plant Instrumentation Program - Integrated Safeguards Experiment staff briefing and an Integrated Safeguards Experiment-Management Team meeting.

E. F. Kurtz, L. T. Hagie, and D. C. Wadekamper visited the United States Atomic Energy Headquarters for an Integrated Safeguards Experiment work session November 19-20, 1970.

\section{B. VISITORS}

The following is a summary of the personnel who visited the General Electric Company Vallecitos Nuclear Center to participate in the Integrated Safeguards Experiment:

1. N. Ovuka and J. Williams, United States Atomic Energy Commission

2. W. Marcuse and S. Suda, Brookhaven National Laboratory

3. W. Murphy, J. Rowan, and C. Smith, National Bureau of Standards

4. R. Borthwick, H. Frittum, E. Lopez-Manchero, A. Masserz, and R. Skjoeldebrand, International Atomic Energy Agency.

\section{CONTRIBUTORS}

The following personnel contributed to the work performed on the Integrated Safeguards Experiment during the quarter ending November 1970:

Task 1

L. T. Hagie and D. C. Wadekamper, General Electric; W. Marcuse, Brookhaven National Laboratory

Task 2

D. M. Bishop, L. T. Hagie, W. A. Nelson, M. N. Robles, J. L. Simpson, and D. C. Wadekamper, General Electric;

R. Parsick, S. Suda, and W. Marcuse, Brookhaven National Laboratory 
General

B. F. Judson, E. F. Kurtz, W. W. Sabol, and M. L. Thompson, General Electric

\section{PREVIOUS REPORTS IN THIS SERIES}

1. Plant Instrumentation First Quarterly Report, April 1970 to .June 1970, GEAP-12114-1.

2. Integrated Safeguards Experiment First Quarterly Report, May 1970 to August 1970, GEAP-12114-2.

3. Plant Instrumentation Program Second Quarterly Report, July 1970 to September 1970, GEAP-12114-3. 
DISTRIBUTION

Division of Technical Information Extension

U. S. Atomic Energy Commission

P. O. Box 62

Oak Ridge, Tennessee

J. M. Williams, Chief

Systems Studies Branch

Office of Safeguards \& Materials Management

U. S. Atomic Energy Commission

Washington, D. C. 20545

Lyman Bryan, Area Manager

U. S. Atomic Energy Commission

Brookhaven Area Office

Upton, New York 11973

H. S. Potter, Chief

New York Patent Gruup

U. S. Atomic Energy Commission

Upton, New York 11973

William Marcuse

3

Brookhaven National Laburatory

Upton, New York 11973 


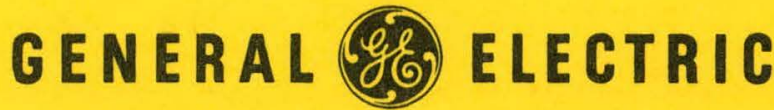

